\title{
FDA seeks to smother Seldane
}

The US Food and Drug Administration (FDA) has begun the process of removing Seldane - a popular antihistamine sold in over 270 countries worldwide and manufactured by Hoechst Marion Rousselfrom the US market because the drug has been associated with potentially lifethreatening heart problems when taken with certain other drugs. However, the third-best selling "non-drowsy" antihistamine in the United States is not regarded as an "imminent hazard," a designation that would require its being withdrawn immediately. But the FDA does believe Seldane's potential risks now outweigh its benefits, because a chemically similar but safer compound is now available (Allegra, also manufactured by Hoechst).

The manufacturer already has announced plans to fight the FDA's decision "to remove a safe and effective product for unnecessary reasons," says Charles Rouse, a spokesman for the Kansas City, Missouri-based company. According to current regulations, the company has the right to - and asked for - a hearing before the agency. Thus it could be months before the matter is resolved in the United States.

But the company is clearly concerned that other countries will follow the US lead. "Those regulatory authorities are free to operate as they choose, but it would be foolish to think that the actions of the FDA wouldn't influence them, because this [the US] is the largest pharmaceutical market in the world," Rouse says. "Actions of this kind certainly would send ripple effects throughout the rest of the world." According to company estimates, Seldane reaped an estimated US $\$ 650$ million in sales in the U.S. and abroad in 1995.

But the FDA's Robert Temple, associate director for medical policy for the agency's Center for Drug Evaluation and Research, says there is no longer any good reason to keep Seldane available. "The risk [of Seldane] is not very large, but Allegra gives you everything [Seldane] gives you, so now we can't think of anyone who would be better off taking Seldane," Temple says. (Although Seldane is sold globally, Allegra only has been licensed thus far in the United States).

The FDA first began receiving reports several years ago of serious and sometimes deadly cardiac arrhythmias in patients who either had liver disease or who were taking other drugs, including ery- thromycin (an antibiotic) and ketoconazole (an antifungal drug). Although other antihistamines that do not cause drowsiness have become available in recent years, the fact that they are chemically different from Seldane made the FDA reluctant to remove Seldane at the time. "We didn't like the idea of getting rid of a molecule, and not all people respond the same way to the same drugs," Temple says. Instead, warnings were added to Seldane's label, and the company launched a massive education program, including letters to doctors, to prevent the drug interactions that might cause the cardiac reaction.

Nevertheless, the company continues to support Seldane's safety for most users. "We will fight the FDA action because there are patients who still benefit from Sel- dane," says Rouse. "We will defend any safety concerns that anyone has about this product." The company does plan, however, to recommend that patients taking Seldane change to Allegra.

Drug interactions appear to cause a build up of terfenadine - the main chemical ingredient of Seldane - in the blood, resulting in heart irregularities. Allegra, on the other hand, contains fexofonadine, the primary active derivative of terfenadine. Fexofonadine does not appear to cause the same cardiac problems when taken with other commonly prescribed medications, thus providing "nearly all of terfenadine's potential beneficial effects," according to the FDA.

MARLENE Cimons Washington, D.C.

\section{Philippine monkey facility closed}

At the end of January, veterinarians employed by the Philippine government carried out the mass euthanization and incineration of 600 monkeys presumably infected with EbolaReston, a filovirus lethal to nonhuman primates. The infected primates had resided at the Ferlite Scientific Research Farm (Manila, Philippines), a facility that exports monkeys to laboratories in Europe and the United States. An outbreak of Ebola-Reston is considered a serious public health risk, because there is a chance the virus could mutate to behave more like its close cousins Ebola-Zaire and Sudan, the two strains that recently killed hundreds of people in Africa.

The problem came to light last spring, when Ferlite supplied the HRP Primate Center (Alice, Texas), with two Ebola-Reston infected macaques. The incident prompted Philippine health officials to quarantine the Ferlite facility. During a follow-up inspection this past January, officials discovered the infection was still circulating and closed the facility. The virus had also apparently spread beyond the cages where it was first detected.

The original cases of Ebola-Reston appeared seven years ago at a research facility in Reston, Virginia. Since that time, importation of nonhuman primates into the US has become more stringent: Imported animals must remain in quarantine for several weeks, and undergo TB tests and a variety of other screening procedures. This waiting period is meant to flush out any endogenous diseases the monkeys may have brought into the country. In the case of HRP's Ebola-infected macaques the system worked, as the monkeys died while in quarantine. As a precaution, HRP killed another 48 primates imported at the same time and housed in the same room.

The risk of primate-to-human disease transmission was a problem for research laboratories long before the this incident. For example, in the 1930 s hepatitis B became the first known simian virus as well as the first recognized to be infectious for man. In 1967, the Marburg virus (also a filovirus) emerged in Germany and Yugoslavia, killing seven laboratory workers exposed to tissues and blood from African green monkeys.

In the past, laboratories largely used only wild-caught nonhuman primates, many of which carried exotic infectious diseases and latent indigenous viruses. Today, most researchers obtain primates from accredited research facilities that are subject to government regulation and inspection by accrediting institutions. One of these, the American Association for Accreditation for Laboratory Animal Care (AAALAC), also offers its services internationally. According to Kathryn Bayne, Director of Accreditation, the Ferlite Facility never sought AAALAC certification.

BARBARA NASTO New York, New York 